\title{
Using experiential learning to enhance nursing student knowledge and attitudes about diabetes self-care
}

\author{
Cynthia Fenske ${ }^{1,2}$, Barbara Freeland ${ }^{1}$, Deborah M. Price ${ }^{* 1}$, Elizabeth Brough ${ }^{1}$ \\ ${ }^{1}$ School of Nursing, University of Michigan, Ann Arbor, Michigan, United States \\ ${ }^{2}$ Concordia University, Ann Arbor, Michigan, United States
}

Received: June 17, 2015

Accepted: September 1, $2015 \quad$ Online Published: September 28, 2015

DOI: $10.5430 /$ jnep.v5n12p104

URL: http://dx.doi.org/10.5430/jnep.v5n12p104

\begin{abstract}
Diabetes is a significant health care issue that requires healthcare providers to be both knowledgeable about the disease and have positive attitudes toward diabetes self-care issues. Nursing students receive a tremendous amount of information about diabetes in their undergraduate education but it is often presented without an opportunity for application. The purpose of this project was to evaluate the effectiveness of an experiential learning innovation with junior level baccalaureate nursing students enrolled in a medical-surgical nursing class. In addition to the traditional classroom presentations, students were randomly assigned to "live with diabetes" (LWD) $(n=106)$ or a control group $(n=109)$. The intervention group students took on one of five diabetic personnas representing the most common treatment regimens for Type I and Type II diabetes. The intervention group reflectively journaled daily about their experiences, observations and thoughts about living with diabetes. The Brief Diabetes Knowledge Test (BDKT) and the Diabetes Attitude Scale (DAS-3) were administered in a pre and posttest fashion at the beginning and end of the diabetes unit of the course. Significant improvement occurred for all students in both knowledge and attitude $(p \leq .005)$. Although the additional effort of providing the LWD experience may enhance the improvements, simply calling attention to the chronicity and demands of diabetes self-care through various experiential learning opportunities may promote student learning and understanding.
\end{abstract}

Key Words: Diabetes mellitus, Problem-based learning, Self-care, Students

\section{INTRODUCTION}

Diabetes is an international health crisis affecting 387 million people in 2014, with an increase in cases reported every year. ${ }^{[1]}$ Treatment of this disease often demands significant lifestyle changes to successfully manage blood glucose levels and reduce the risk of serious complications. Nurses have an important role in helping people understand and manage the complexities of diabetes, yet these concepts are difficult to teach nursing students in a traditional classroom setting. Traditional teaching methods in the classroom can be devoid of integrative strategies and provide minimal opportunities for nursing students to develop an understanding of the patient perspective in living with a chronic illness, such as diabetes. $^{[2]}$ Benner et al. discussed the need for methods that facilitate the growth of clinical imagination so that students could learn to be more flexible and insightful in the application of knowledge in practice. ${ }^{[2]}$

The purpose of this project was to evaluate the effectiveness of an experiential teaching methodology on improving junior baccalaureate nursing students' knowledge and attitudes

\footnotetext{
*Correspondence: Deborah M. Price; Email: debprice@umich.edu; Address: School of Nursing, University of Michigan, 400 N. Ingalls, Suite 2350, Ann Arbor, Michigan, United States.
} 
about diabetes self-care. A week long "living with diabetes" (LWD) opportunity was developed for the students enrolled in the didactic portion of a medical-surgical nursing course. The authors anticipated that the LWD experiential learning approach would have a positive impact on the students' knowledge and attitudes toward diabetes self-care.

\section{Background}

Nurses play a vital role in helping people with diabetes manage their disease, therefore it is essential that student nurses understand the challenges facing these patients. Beverly et $a l$. found that people with diabetes felt providers did not understand or appreciate the difficulties of living with diabetes or its' complications and many noted that that their care was not individualized. ${ }^{[3]}$ This may be partially related to lack of knowledge about diabetes care among health care practitioners. ${ }^{[4]}$ Griffis et al. discovered that acute care nurses had large gaps in their knowledge of diabetes specifically in the areas of therapies and medications. ${ }^{[5]}$ Similarly, Spollett reported results of previous studies of nurses' understanding of diabetes which included poor comprehension of the basics of diabetes, self-care management, and medications. ${ }^{[6]}$ Chan and Zang identified in their study that the nurses with the least amount of education and the fewest years of nursing experience had the lowest level of diabetes knowledge. ${ }^{[7]}$ These findings indicate a lack of knowledge and understanding of diabetes and self-care management among practicing nurses, and suggest a need for a more compelling and integrative approach for educating nursing students about diabetes. A memorable and experiential approach may enhance knowledge by helping students recognize the complexity involved with the treatment and management of this disease.

Sharp and Lipski found that educational programs positively affected attitudes toward diabetes. ${ }^{[8]}$ Health behavior change models suggest that it is the attitudes of the health care providers, rather than their level of knowledge, that most interferes with the lack of change seen in their clinical behaviors. ${ }^{[8]}$ Attitudes toward diabetes, not knowledge have been significantly associated with good diabetes management. ${ }^{[9]}$ Studies have shown that educational programs positively affect attitudes toward diabetes, generally in all five areas on the Diabetes Attitude Scale (DAS) (need for special training, seriousness of diabetes, need for control, impact of diabetes, and patient autonomy) immediately following the program, but these changes do not persist over time. ${ }^{[8]}$ A number of studies found that it was attitudes toward diabetes, not knowledge that were significantly associated with good diabetes management and concluded that people with diabetes are most concerned with the impact of the disease on their lives while healthcare providers see diabetes as a pathophysiologi-

Published by Sciedu Press cal issue and focus their concern on the physical impact the disease presents to their patients. ${ }^{[5,9-11]}$ This difference in perspectives may be a contributing factor to poor management of diabetes.

Kolb's Experiential Adult Learning Theory was selected as the framework for the implementation of the proposed teaching methodology in this study. ${ }^{[12]}$ Kolb describes experiential learning as "the process whereby knowledge is created through the transformation of experience" (p. 38). This theory emphasizes several critical aspects of the learning process, including 1) the process of adaptation and learning as opposed to content and outcomes, 2) that knowledge acquisition is a transformational process with new knowledge continuously being created and recreated, and that 3) learning transforms the experience subjectively and objectively. ${ }^{[12]}$ Learning styles are based on a four-stage learning cycle that encompasses a concrete experience, reflection, abstract conceptualization and active experimentation. ${ }^{[12]}$ Kolb asserts that all stages of the cycle must be experienced for learning to be effective.

Experiential learning appears to be an effective way for students to learn and practice first-hand the issues and complexities of managing diabetes. Two studies with pharmacy students used participation in a simulation of living with diabetes. ${ }^{[13,14]}$ Both studies showed an increase in confidence in the ability to teach others how to manage diabetes. Nurse practitioner and undergraduate nursing students who simulated the management of type 1 diabetes regulated by an insulin pump demonstrated an increased understanding of the difficulties and inconvenience of living with type 1 diabetes, particularly in the areas of dietary changes, living with an insulin pump, and monitoring blood glucose. ${ }^{[4]}$ Vogt, Chavez, and Schaffner provided nursing students with the opportunity to care for children with diabetes while at a summer camp. ${ }^{[15]}$ Their results showed students had increased knowledge and confidence about caring for children with diabetes, while simultaneously developing empathy for the lifestyle of these children.

Lisko and O'Dell utilized Kolb's theory with junior-level nursing students in a medical-surgical nursing course to meld simulated critical thinking opportunities and laboratory skill performance. ${ }^{[16]}$ Overall evaluation of the experience by students and faculty was positive identifying that these new learning strategies can be used to facilitate the nursing student's critical thinking abilities. Similarly, Van Son and Fitzgerald utilized Kolb's theory to structure development of a "Sensory Kit" as a low cost active learning strategy to assist nursing students in understanding sensory changes that occur in geriatric patients. ${ }^{[17]}$ Both studies identified the benefits of 
experiential learning to student understanding of the health and functional needs of patients.

\section{Methods}

After receiving Institutional Review Board approval, this project was instituted with 237 junior nursing students from a large Midwestern University enrolled in a semester long medical-surgical nursing course. Each student received an information sheet briefly outlining the study purpose, requirements, and voluntary nature of participation. Students who chose to participate were randomized to either a control group or the LWD group. Students within the LWD group were randomized to one of five diabetes personas, representing the most common treatment regimens for types 1 and 2 diabetes (see Table 1). The LWD group was asked to live as though they had diabetes and to follow a specific treatment plan for one week. A total of 242 students chose to participate over a period of 4 semesters during 2013-2014. Data collected from 237 of the participating students was included in the analysis sample. Five observations were dropped due to incomplete data. Approximately 49 percent $(\mathrm{N}=117)$ of the students were in the in the LWD experience group and $51 \%(\mathrm{~N}=120)$ were in the control group.

Table 1. Diabetes Persona's

\begin{tabular}{|c|c|c|c|c|c|}
\hline & DM Type 1 & DM Type 1 & DM Type 2 & DM Type 2 & DM Type 2 \\
\hline Medication & $\begin{array}{l}\text { Multiple daily } \\
\text { injections of insulin }\end{array}$ & Insulin pump & $\begin{array}{l}\text { Metformin twice } \\
\text { daily }\end{array}$ & $\begin{array}{l}\text { Metformin } \\
\text { Sitagliptin } \\
\text { Twice daily }\end{array}$ & $\begin{array}{l}\text { Multiple daily } \\
\text { injections of insulin }\end{array}$ \\
\hline $\begin{array}{l}\text { Glucose } \\
\text { Monitoring }\end{array}$ & $\begin{array}{l}4 \text { times a day, } \\
\text { with meals \& } \\
\text { bedtime }\end{array}$ & 8 times a day & Daily, fasting & $\begin{array}{l}\text { Fasting and before } \\
\text { dinner }\end{array}$ & $\begin{array}{l}4 \text { times a day, with } \\
\text { meals \& bedtime }\end{array}$ \\
\hline Meal Plan & $\begin{array}{l}\text { 55-65 grams of } \\
\text { carbohydrate per } \\
\text { meal }\end{array}$ & $\begin{array}{l}\text { Carbohydrate } \\
\text { counting }\end{array}$ & $\begin{array}{l}\text { 60-65 grams of } \\
\text { carbohydrate per } \\
\text { meal }\end{array}$ & $\begin{array}{l}60-65 \text { grams of } \\
\text { carbohydrate per } \\
\text { meal }\end{array}$ & $\begin{array}{l}\text { 50-65 grams of } \\
\text { carbohydrate per } \\
\text { meal }\end{array}$ \\
\hline $\mathrm{A} 1 \mathrm{C}$ & 7.2 & 8.8 & 6.9 & 10.8 & 12.2 \\
\hline
\end{tabular}

Each student in the LWD group was provided with a glucose meter, test strips and control solution, simulated medication, a carbohydrate controlled meal plan, and a digital video disc of general diabetes self-care information. A small university grant covered the cost of supplies. Students were asked to simulate glucose monitoring using control solution at each occasion that their persona was required to test, between one and eight times a day. Blood glucose numbers were created based on a simulated A1c assigned to each persona. These glucose numbers were provided to the student in a blinded manner to prevent the students from knowing what their blood glucose was until the appropriate time. Simulated oral diabetes medication was also provided in candy form labeled as the persona's prescription. Test medium filled insulin pens were provided for personas that required insulin injections. Students whose persona had type 1 diabetes using an insulin pump were provided with one and asked to "wear" it 24 hours a day. To avoid personal injury, no lancing devices or insulin injection materials were provided. Students were asked to carry their diabetes supplies with them as if they had diabetes. For meal planning, students were encouraged to use a cell phone application to assist them in counting carbohydrates according to their prescribed meal plan. Other than a traditional didactic classroom lecture presenting an overview of diabetes in adults, students were given only a brief orientation to diabetes self-care. This was done purposely to simulate what many people newly diagnosed with diabetes might receive in an initial office visit.

To add realism to the LWD experience, students received text messages from one of the authors that described scenarios common to people living with diabetes (see Table 2). Students received between three and seven text messages during the one week LWD experience. The authors were available to answer questions regarding all aspects of diabetes self-care to simulate contact with a healthcare provider.

The LWD group was required to journal daily about managing their persona's diabetes self-care. Specifically, students were encouraged to discuss barriers to carrying out the requirements of self-care related to meals, medications, blood glucose monitoring, personal relationships, and exercise. Additionally, journal entries were to reflect challenges related problem solving skills needed to respond to the situational text messages and to discuss feelings about the entire experience of LWD.

All students received the same diabetes course content taught concurrently with the LWD experience. In-class material included a lecture by a certified diabetes educator that cov- 
ered pathophysiologic basics, complications, medications, values assessment, changes in the patient's condition, patient and self-care for both type 1 and type 2 diabetes. Additionally, class time was spent in groups working through case studies for both type 1 and type 2 diabetes. The cases required students to apply their knowledge to the various patient scenarios that incorporated medications, laboratory education, and self-care practices including various diabetes monitoring and insulin administration equipment. A dietitian, also a certified diabetes educator, spoke to the students about diet and exercise in diabetes, including a practice session of carbohydrate counting.

Table 2. Text messages

\begin{tabular}{ll}
\hline Topic & Message \\
\hline \multirow{3}{*}{ Food } & You are attending a party tonight. Pizza, beer, snacks \\
& No time for lunch today \\
& Birthday party at work or school today for friend - cake and ice cream - your favorite flavors \\
& Got the flu, too sick to eat \\
& Your blood sugar is now 52 \\
Glucose Control & Bedtime glucose is 268 \\
& Forgot to take insulin this morning \\
& Forgot diabetes pills - out to dinner \\
& Took pills this morning but forgot to eat breakfast \\
& Realized this morning that you forgot glargine last night \\
Medications & Took insulin based on what you thought you would be eating and then you got full and didn’t finish, or the \\
& portion was smaller/bigger than expected/got sick and couldn’t eat it and now can't keep anything down \\
& You are going to the gym for 60 min workout \\
& Insulin pump battery died - 2 miles into a 4 mile hike \\
& Boss assigned you to midnights shift for one week \\
Exercise & Family and job stress BIG TIME \\
& You are out to lunch, needle disposal where? \\
Forgot to bring meter \& insulin pen when eating out
\end{tabular}

\section{Evaluation}

All students were administered the Michigan Diabetes Research and Training Center Brief Diabetes Knowledge Test (BDKT) and the Diabetes Attitude Scale (DAS-3) in a pretest post-test fashion at the beginning and the end of the diabetes unit of the course. The BDKT is a 23-item test that has been used as a measure of general diabetes knowledge and covers topics such as the disease process, insulin use, treatments and side effects. Item responses were scored 1 if correct and 0 if incorrect then summed to construct the test score. The test was shown to have adequate reliability $(\alpha=0.71)$ and validity among adults with diabetes in prior research. ${ }^{[18]}$ The DAS-3 questionnaire was designed to evaluate attitudes toward diabetes using a five point Likert scale ranging from "strongly agree" to "strongly disagree". This instrument has been found to be valid and reliable when used with patients and healthcare providers. ${ }^{[19]}$ The instrument, developed by the Michigan Diabetes Research and Training Center, includes five sub-scales of self-reported attitudes including the need for special training, the seriousness of type 2 diabetes, the value of tight glucose control, the psychological impact of diabetes, and patient autonomy. ${ }^{[19]}$

Data were analyzed using the Statistical Package for Social Sciences Version 22 (SPSS Inc., Chicago, Il, USA). Students' demographic characteristics and knowledge test scores were summarized using descriptive statistics. Pre-test and posttest scores were compared for the sample overall using a paired t-test. Models predicting post-test knowledge by intervention group, by persona group, and by type of diabetes were estimated using ANCOVA with baseline knowledge as a covariate.

Students' demographic characteristics are summarized in Table 3. Most of the students $(45.5 \%)$ were between 18 and 20 years of age. The sample was predominantly female $(85.5 \%)$ and most of the students were Caucasian $(75.5 \%)$.

The BKDT and DAS-3 scores were evaluated before and after the implementation of the teaching innovations for all participating students. The pre-tests and post-tests were given three weeks apart. No significant differences were seen in baseline 
knowledge between the control and LWD experience groups, among students who experienced the 5 different personas, or by diabetes type 1 or 2 . Age, ethnicity, gender and having an immediate family member with diabetes were also not significantly associated with baseline knowledge. Overall knowledge significantly increased from pre-test $(\mathrm{M}=18.07$, $\mathrm{SD}=2.32)$ to post-test $(\mathrm{M}=19.29, \mathrm{SD}=1.61)$ for all students $(t=-7.72, p=.000)$. Knowledge scores are the sum of the correct items out of 23 questions, with a maximum score of 23. While we expected knowledge to increase at post-test for all students, we also expected that the LWD group would show a greater gain. To further explore the effects of the personas used within the LWD group, we controlled for pretest knowledge. No significant differences emerged by individual persona. However, significant differences were demonstrated when pretest knowledge was taken into account and the five LWD personas were collapsed into two groups: those who had "lived with" type 1 and those who "lived with" type 2 diabetes $(\mathrm{F}=3.14, p=.05)$. Students who enacted a type 1 diabetes persona had a greater gain in knowledge $(M=20.0)$ when compared to those who enacted type 2 diabetes persona $(M=19.34)$ or those in the control group $(M=19.15)$.

Table 3. Sample characteristics

\begin{tabular}{ll}
\hline & N (\%) \\
\hline Age (years) & $110(45.5)$ \\
$18-20$ & $77(32.1)$ \\
$21-23$ & $15(6.3)$ \\
$24-26$ & $9(3.8)$ \\
$27-29$ & $17(7.1)$ \\
$30+$ & \\
Gender & $204(89.5)$ \\
Female & $24(10.5)$ \\
Male & \\
Ethnicity & $18(8.0)$ \\
Asian & $11(4.9)$ \\
Hispanic & $11(4.9)$ \\
African American & $179(79.2)$ \\
Caucasian & $7(3.1)$ \\
Other & \\
Persona & $26(11)$ \\
1 & $21(8.9)$ \\
2 & $24(10.1)$ \\
3 & $23(9.7)$ \\
4 & $22(9.3)$ \\
5 & $121(51.1)$ \\
Control & \\
Has a family member with diabetes & $41(17.1)$ \\
Yes & $184(76.7)$ \\
No &
\end{tabular}

Note. N's fluctuate due to missing data
Attitudes subscale scores changed significantly from pre-test to post-test for all students in both the LWD and control groups $(\mathrm{F}=7.32, p<.001)$. But, no significant differences in attitude scores emerged between the LWD group and control group. $(\mathrm{F}=.91, p=.041)$. Testing for additional variables such as age and exposure to others with diabetes also did not emerge as significant.

Qualitative analysis of the student's reflective journals was completed using the Smith and Firth Framework. ${ }^{[20]}$ The students' journals showed themes of a developing appreciation of the complexities, responsibilities and burdens of diabetes self-care (see Table 4). Observations were related to the complexity of carbohydrate counting, discipline in staying within a meal plan, disposal of sharps in public areas and the constancy diabetes self-care management. Some students experienced anxiety and/or frustration related to making correct self-care decisions, or felt peer pressure related to compliance issues. It was evident that LWD students recognized the need for critical thinking and problem solving skills when they received text messages reporting various blood glucose levels. Samples of written work from the experiential group were thoughtful, insightful, and demonstrated care and compassion. For example students wrote:

"I was surprised that my before dinner blood glucose was 260. I was expecting it to be less and for me to be able to eat more carbs at the buffet."

"So tonight at dinner I took my appropriate amount of insulin and finished my meal. However, I am now nauseated and vomiting. I don't know what to do because I am now nervous that my blood sugar will be too low since I was not able to keep any of my meal down."

\section{Discussion}

It was anticipated there would be significant differences between the LWD and control groups, but unexpectedly there was improvement in both groups. It appeared that simply calling attention to the topics involved with diabetes self-care had positive effects on improving both knowledge and attitudes. The LWD activity was perceived by the majority of students as novel and created a lot of excitement in the classroom. This likely contributed to an increased interest in the topic resulting in more discussion and sharing about student's experience with patients who have diabetes. Interestingly, a significant change in knowledge, but not attitudes, occurred for students who assumed the type 1 diabetes personas. The increase in knowledge could be due to the increased personal involvement and attention to self-care that is required. This same involvement and attention may have also made students realize how inexperienced they were with diabetes self-care management, therefore attitudes didn't change as expected. 
Table 4. Journal excerpts

LWD Group
I want to go to this party; I want to feel like a normal college kid... My friends don’t understand that I am not “allowed” to have this
kind of food and fun anymore. They say things like, “One brownie isn’t going to kill you”. Yeah, maybe not instantly, I think to
myself. I end up giving in to peer pressure and have two beers and a brownie (46 carbs).
It can sometimes be too much effort to figure out carbs.
It's really hard to keep up with blood sugars while at work. It was nearly impossible to slip away around noon to get a reading.
I'm so surprised that even after doing this project for almost a week, I still slip up. I walked out the door this morning without my
insulin pens.
If I go out, I have to bring a purse to fit everything, whereas normally I’d just shove some cash and my license in my pocket.
I feel as if carrying around my brown bag full of diabetes things makes me look different and weird to other people. I feel like people
are staring at me. I have needle anxiety, although we don’t actually have to use a needle for this study, I am anxious even thinking
about potentially having to give myself injections daily.

Changes in knowledge and attitudes seen in the control group may have been attributed to interaction and with students who were in the LWD group. Anecdotally, students reported discussing the LWD experience with their peers during the study. The authors noted that all students in the class were interested in the experiential teaching innovation and some who were in the control group expressed disappointment at not being the LWD group. Additionally, all students studied for a content exam on diabetes in the medical-surgical class (given prior to the post-test), which may have also influenced their post-test knowledge scores and attitudes.

Written student journal reflections in the LWD group suggested that the act of thinking and writing may have played an important role in the development of sensitivity for the demands of diabetes self-care. Writing about an experience allows people to keep the events more readily accessible in their memory and causes them to think about the events in different ways. ${ }^{[21]}$ This then alters the individual's overall representation of the events in their memory. Thus, the changes that we saw in the LWD group may be related to the assimilation of thoughts into memory from the writing tasks. Reflective learning journals have been recognized as an effective strategy in the promotion of learning in nursing students. Blake described the value of journaling in nursing education as a process which can connect theory with feelings, instill values of the nursing profession and allows students to understand the perspective of their patients. ${ }^{[22]}$ Epp reviewed 9 studies which used reflective journaling in nursing education, and reported that evidence supports journaling use for the purpose of learning. ${ }^{[23]}$ Similarly O'Connell and Dymont identified that benefits of journaling included creativity and critical reflection. ${ }^{[24]}$

After evaluating the LWD experience we realized all students were learning about and discussing diabetes management in class during the intervention period. This immersion

Published by Sciedu Press may have reduced our ability to show differences among the groups. Additionally, the resource-intensive nature of preparing supplies and delivering multiple text messages for the LWD group was burdensome for faculty. Providing an active-learning/hands-on exposure in a classroom or laboratory setting to the tools of diabetes self-care may be a more efficient method to enhance learning.

Additional limitations of this study include the lack of generalizability due to the use of a small, convenience sample from a single, large university. There was an absence of control of contextual and confounding variables, such as previous personal or professional experience with diabetes self-care or diabetes knowledge. Also, upon return of supplies provided from the LWD group, it was evident that some did not fully use the self-care materials. Interactions between the LWD and control groups were not controlled during the intervention period, which may have reduced our ability to show differences among the groups.

\section{Conclusion}

The LWD intervention was an engaging activity that called attention to the challenges of diabetes self-care for junior baccalaureate nursing students. The use of personas and reflective journaling added to the realism of the experiential learning opportunity. Both the control and the LWD group showed positive changes in knowledge and attitudes, likely due in part to the excitement the LWD experience created in the classroom, which placed attention on the topic of diabetes self-care. The experience of journaling may be an effective means to facilitate learning, engagement, empathy and critical thinking about diabetes self-care when added to the traditional pedagogical methods of classroom presentations and problem-solving exercises. Preparing self-care supplies and sending text messages was labor intensive for faculty, cost prohibitive and therefore not sustainable. Al- 
though the additional effort of providing the LWD experience may enhance the improvements, simply calling attention to the chronicity and demands of diabetes self-care through various experiential learning opportunities may promote student learning and understanding.

\section{CONFlicts OF INTEREST Disclosure}

The authors declare that there is no conflict of interest statement.

\section{REFERENCES}

[1] International Diabetes Federation, Diabetes Atlas 6th Ed. International Diabetes Federation website. 2014.

[2] Benner P, Sutphen M, Leonard V, et al. Educating Nurses: A Call for Radical Transformation. Washington D.C.: Carnegie Foundation 2010.

[3] Beverly E, Wray A, Chiu C, et al. Older adults' perceived challenges with health care providers treating their type 2 diabetes and comorbid conditions. Clin Diabetes. 2014; 32: 12-17. PMid:26246673 http://dx.doi.org/10.2337/diaclin.32.1.12

[4] Freeborn D, Roper S, Dyches T, et al. The influence of an insulin pump experience on nursing students' understanding of the complexity of diabetes management and ways to help patients: A qualitative study. Journal of Nursing Education and Practice. 2013; 3(3): 52-60. http://dx.doi.org/10.5430/jnep.v3n3p52

[5] Griffis S, Morrison N, Beauvais C, et al. Identifying continuing diabetes education needs of acute care nurses in Northern Ontario. Can J Diabetes. 2007; 31(4): 371-377. http://dx.doi .org/10.1016 /S1499-2671(07) 14009-0

[6] Spollett G. Promoting continuing education in diabetes management. Endocr Pract. 2006; 12(Suppl. 3): 68-71. PMid:16905520 http://dx.doi.org/10.4158/EP.12.S3.68

[7] Chan MF, Zang YL. Nurses' perceived and actual level of diabetes mellitus knowledge: Results of a cluster analysis. J Clin Nurs. 2007; 16(7B): 234-242. PMid:17584433 http://dx .doi .org/10.1111 /j.1365-2702.2006.01761.x

[8] Sharp L, Lipsky M. Continuing medical education and attitudes of health care providers toward treating diabetes. J Contin Ed Health 2002; 22: 103-112. PMid:12099119 http://dx.doi .org/10.10 02/chp. 1340220206

[9] Norris S, Engelgau M, Narayan K. Effectiveness of self-management training in type 2 diabetes: a systematic review of randomized controlled trials. Diabetes Care. 2001; 24: 561-587. http://dx.doi.o $\mathrm{rg} / 10.2337 /$ diacare.24.3.561

[10] Weinberger M, Cohen S, Massuca S. The role of physicians' knowledge and attitudes ineffective diabetes management. Soc Sci Med. 1984; 19: 965-969. http://dx.doi.org/10.1016/0277-953 6(84) 90326-5

[11] Cohen M, Tripp-Reimer T, Smith C, et al. Explanatory models of diabetes: patient-practitioner variation. Soc Sci Med. 1994; 38: 59-66. http://dx.doi.org/10.1016/0277-9536 (94) 90300-X

[12] Kolb DA. Experiential Learning: Experience as the Source of Learning and Development Vol. 1. Englewood Cliffs, NJ: Prentice-Hall; 1984.
[13] Westberg S, Baumgardner M, Brown M, et al. Impact of an elective diabetes course on student pharmacists' skills and attitudes. Am J Pharm Edu. 2010; 74(3): 1-7. http://dx.doi.org/10.5688/a j740349

[14] Delea D, Shrader S, Phillips C. A week-long diabetes simulation for pharmacy students. Am J Pharm Edu. 2010; 74(7): 1-8. http://dx.doi.org/10.5688/aj7407130

[15] Vogt MA, Chavez R, Schaffner B. Baccalaureate nursing student experiences at a camp for children with diabetes: The impact of a service-learning model. Pediatr Nurs. 2006; 37(2): 69-73.

[16] Lisco S, O'Dell V. Integration of theory and practice: Experiential learning theory and nursing education. Nurs Educ Perspect. 2010; 31(2): 106-108

[17] Van Son C, Fitzgerald C. The "Sensory Kit": Teaching about sensory changes in older adults. Nurs Educ Perspect. 2012; 33(3): 201-203. PMid:22860490 http://dx.doi.org/10.5480/1536-5026-33. 3.201

[18] Fitzgerald J, Funnell M, Hess G, et al. The reliability and validity of a brief diabetes knowledge test. Diabetes Care. 1998; 21: 706710. PMid:9589228 http://dx.doi.org/10.2337/diacare.2 1.5 .706

[19] Anderson R, Fitzgerald J, Funnell M, et al. The third version of the diabetes attitude scale (DAS-3). Diabetes Care. 1998; 21(9): 1403 1407. http://dx.doi.org/10.2337/diacare.21.9.1403

[20] Smith J, Firth J. Qualitative data analysis: the framework approach. Nurs Res. 2011; 18(2): 52-62. PMid:21319484 http://dx.doi.o $\mathrm{rg} / 10.7748 / \mathrm{nr} 2011.01 .18 \cdot 2.52 . \mathrm{c} 8284$

[21] Chung C, Pennebaker J. Revealing dimensions of thinking in open-ended self-descriptions: An automated meaning extraction method for natural language. J Res Pers. 2008; 42(1): 96132. PMid:18802499 http://dx.doi.org/10.1016/j.jrp. 200 7.04 .006

[22] Blake TK. Journaling; An active learning technique. Int J Nurs Scholarsh. 2005.

[23] Epp S. The value of reflective journaling in undergraduate nursing education: A literature review. Int J Nurs Stud. 2008; 45: 13791388. PMid:18325522 http://dx.doi.org/10.1016/j.ijnur stu.2008.01.006

[24] O'Connell TS, Dyment JE. The case of reflective journals: Is the jury still out? Reflective Practice. 2011; 12: 47-59. http: //dx.doi.org/10.1080/14623943.2011.541093 